\title{
The perceived value of the National association of schools of art and design (NASAD) accreditation by fashion students in fashion programs at public and private colleges in Southern California
}

\begin{abstract}
This survey-based quantitative descriptive and correlational study was conducted to examine the perception of the National Association of Schools of Art and Design (NASAD) accreditation by fashion students in fashion programs at public and private colleges. Designated by the United States Department of Education, NASAD is the premier accrediting agency for freestanding institutions, and art/design and art/design-related programs (both degree- and non-degree-granting), throughout the United States (NASAD 2016-17, pg. 1). Fifty students enrolled in fashion programs at a 4-year California State University (CSU) public college and (b) fifty students enrolled in fashion programs at a 4-year private college were asked questions regarding their awareness, familiarity or the perceived value of NASADs' accreditation standards for fashion programs. The findings of this study suggest that $(80 \%)$ of fashion students in the Southern California area surveyed, were unfamiliar with NASAD standards for fashion programs, and $(86 \%)$ were unaware or did not know if they were attending a NASAD-accredited program. Although, out of 100 students surveyed $(57 \%)$ believed there was or should be some type of value placed on specialized accreditation for fashion programs, even though they were not aware or familiar with NASAD.
\end{abstract}

Volume 4 Issue 3 - 2018

\section{Cynthia R Williams}

Lecturer on Apparel Design and Merchandising, California State University Northridge (CSUN), USA

Correspondence: Cynthia R Williams, Ed D, College of Health \& Human Development, Apparel Design \& Merchandising (ADM) area of Department of Family Consumer Sciences, California State University Northridge (CSUN), 18I I I Nordoff St. Northridge, CA 93030, USA, Tel (8I8) 564-875I, Email cyrestudios I@hotmail.com, cynthia.williams@csun.edu

Received: May 30, 2018 | Published: June 20, 2018

Keywords: NASAD, on-the-job skills, job-readiness, fashion design curriculum

\section{Introduction of the problem}

When one thinks of the fashion industry, one might think of famous designers and celebrity fashion shows. Today, fashion is a $\$ 1.2$ trillion global industry, employing 1.9 million people in the United States, creating a positive impact on regional economies across the country. ${ }^{1}$ Presently, $90 \%$ of apparel design and production has gone overseas or elsewhere in the world. ${ }^{2}$ Manufacturing today requires "universal participation"; 3 meaning garments designed in one country, made in fabric from a second country, assembled in a third country, then shipped back to the country of the original design, to be sold at retail in a matter of weeks.

In the past, all one needed to know was some sewing skills, fabric knowledge and garment construction to begin a career in fashion. Today, a career in fashion requires a different set of skills, making fashion education more prevalent and crucial than ever before. The interest in a fashion career has grown over the last decades, requiring many schools once offering degrees in home economics to revisit their fashion courses revamp their curriculum and rehire faculty with academic degrees, who are currently out in the fashion field. But do students know what actual skills are needed to transition from the classroom out into the field, or recognize good indicators of what a fashion program should offer? This quantitative survey-based descriptive and correlational study was conducted to examine the perception of the National Association of Schools of Art and Design (NASAD) accreditation by fashion students in fashion programs at public and private colleges in Southern California.

Proponents for specialized accreditation agencies, specifically, NASAD, give status and relevance to the instruction and quality of a particular fashion program. Accreditation often attracts quality faculty and students with knowledge of the benefits accreditation offers. ${ }^{4-11}$

The Department of Education (DOE) has designated NASAD as the specialized accreditation for art/design and art/ design-related programs (both degree- and non-degree-granting), in the US (NASAD 2016-17, pg. 1). NASADs' Standard Development Curriculum (SDC) represents the curriculum, standards, and guidelines along with the knowledge, methods, and history of the fashion industry. ${ }^{12}$ Their standards are based on the skills of professionals who work in this field.

According to NASADs' SDC mission, institutions with a sufficient number of qualified working fashion design faculty, contemporary technological resources, and comprehensive curricula, including core and specialized courses in fashion design, have the prerequisites to offer fashion design degrees of quality to prepare students for entrylevel professional practice in fashion design. ${ }^{12}$ Examples of NASADs' quality requirements for accreditation include:

a. Curricular Structure, (b) Course Studies and (c) Essential Competencies and Collaborative skills beyond the classroom:

b. Curricular Structure content and time requirements focus on developing the skill competencies expected from a baccalaureate degree program in fashion design (Standard VIII).

c. Course Studies include in art and design make-up 25-35\% of the fashion program, art and design history represent $10-15 \%$, and GE studies (business, math and social science) represent 25 $35 \%$, while the history of art and design represent $65 \%$ of the curriculum (Standard VIII.A.6 / III.C). 
d. Essential Competencies include collaborative skills, such as internship (industry working requirements) required before graduation (Standards VIII.B. and C).

NASAD answers Frequently Asked Questions on their website regarding how students can apply to art/design schools and for prospective student's familiar with NASAD, this knowledge can be used as a good indicator of what a fashion program entails. As a designated accrediting agency by the DOE, a perceived value has been placed on NASAD; but for those fashion students who are not aware of the perceived value placed on NASAD accreditation, are they informed about what makes a competent fashion program?

According to the NASAD mission, ${ }^{12}$ NASAD accreditation assures students, parents and other stakeholders that accredited institutions offering art and design programs provide competent teachers, efficient studios, and contemporary curricula to help students make the transition from the classroom to the industry. The NASAD accreditation seeks to establish a national voice for matters pertaining to visual arts and design programs. Most importantly, by means of the NASAD accreditation, it encourages institutions to consistently give students a sound basis for significant future accomplishments in art and design. If the NASAD accreditation is the stamp of approval for what fashion education should entail, are prospective students aware or familiar with NASAD as a good indicator of what a quality fashion program should entail? As prospective students continue to become interested in a fashion career, choosing where to start their education should be important, especially for those not aware of how to make their dream of being in the fashion industry happen. Certainly, having knowledge of where and how to receive a good fashion education could start with an accredited art/design school. Students with or without the knowledge of NASAD may be looking for a fashion degree, and may choose to attend a school based on other criteria that have nothing to do with a quality education. But is attending a NASAD-accredited school fashion program important? Before one can answer that question, one should have some background knowledge as to why the awareness of NASAD should be important among students regarding the factors to consider deciding which institution and fashion program to attend?

\section{Fashion industry}

The fashion industry has been in reconstruction mode over the last several decades, since $90 \%$ of apparel design and production has gone overseas or elsewhere in the world. ${ }^{2,13}$ No longer is a garment designed and produced in one location or the same location as the designer or production contractor. This type of global trade now requires universal participation to provide fashion products for a fast turnaround, referred to as fast fashion. Lowson, King, and Hunter defined fast fashion as quick manufacturing at an affordable price for a quick turnaround ${ }^{14}$ Fast Fashion became a market-based model in the late 1990s, and is now part of the current manufacturing protocol Lowson et al. ${ }^{14}$ Global participation is the new method of creating garments. No longer is a garment just designed and produced in the US where the designer or production contractor is located; garments are designed in one country, made in fabric from the second country, assembled in a third country, then shipped back to the country of original design to be sold. The whole operation, from original sketch to retail floor, can take only a matter of weeks.

\section{Fashion education}

Today, universal participation requires restructuring of fashion education. In the past, all one needed to know was how to sew, some fabric draping techniques, and some pattern skills to begin a career in fashion in the US. Global manufacturing requires relevant courses that parallel industry needs. Courses such as Technical Design, Computer Pattern-making, Computer-Aided-Design (CAD) and Designer Tech Packs for design implementation overseas. These courses are pertinent to (a) instruction from teacher's current in the industry, and (b) instruction that correctly prepares students with practical skills conducive to the new standard of producing fashion goods all over the world.

\section{Fashion programs}

Three hundred plus college or universities awarding degrees in areas of Apparel Design, Merchandising \& (ADM) after manufacturing have been awarded specialized accreditation (NASAD) to the institution or granted programmatic accreditation to a particular department or program within the institution. ${ }^{15}$ NASAD accreditation status has long been recognized as the quality of regional, career-related and programmatic accrediting organizations, an affirmation to students, parents, faculty, and staff that a school has met critical standards and is fully qualified as a program or institution to offer quality education in a particular field..$^{15}$

\section{Accreditation for fashion programs}

There are two types of accreditations many 4-year public and private schools use: the American Association of Family and Consumer Sciences (AAFCS) certification for family consumer/home economic education and NASAD accreditation for art and design education. Some state schools are accredited to cover all aspects of sewing and art and design curricula through both NASAD and AAFCS. ${ }^{16}$ Under AAFCS, not all Family Consumer Sciences (FCS) programs will necessarily offer specific courses or provide the industry connections needed for a smooth transition into the fashion trade. The evolution of fashion education is forcing 4-year public schools still offering FCS degrees, in apparel design and merchandising (like AAFCS) to rewrite a more structured standard focus, research and outcomebased course criteria to substantiate that FCS programs are essential to students interested in fashion degrees. ${ }^{17}$ This includes curriculums with broad-based conceptual frameworks that include critical and creative thinking and problem-solving related to present and future applications of skills and concepts (i.e., education for more than just learning to sew) (p. 26). In contrast, NASAD accreditation is specific to the evolving field of creativity and production, as well as industrial design for schools that combine art and design with an emphasis on industry partnerships as part of the industry learning process for both public and private colleges. ${ }^{12}$ NASAD-accredited programs represent structured curricula focusing on practical art and design course content such as fashion illustration, computer-aided design (CAD), perfected design presentations, historical and theoretical thinking toward the creative design process through internship and collaborative study with industry leaders.

\section{Fashion students}

In Bill's 2003 article she suggests that students who pursued creative degrees believed being a designer meant designing mainly with a sketchbook and directing a group of able production people (pg. 13). Do students really understand what is involved in fashion manufacturing? Can students who are familiar with NASAD accreditation recognize a quality fashion education? Does their 
knowledge of NASAD influence their decision to attend a particular program at a public or private college? For those fashion students who are not aware of the perceived value placed on NASAD accreditation, are they informed about what makes a competent fashion program? Is it possible that students who are looking for a fashion degree look to attend a school based on other factors?

\section{The problem}

The problem with today's fashion education is that a career in fashion requires a different set of skills than in the past; making fashion education more crucial than ever before. This means that relevant courses that parallel the new industry needs for a successful transition from academics classrooms into the field are pertinent. Researching other studies regarding accreditation, fashion education and why students pursue a career in fashion has uncovered a gap between what students should expect to learn during their fashion education training and most importantly, can students recognize good indicators such as the perceived value of NASADs' SDC for fashion programs. There are studies regarding accreditation, fashion education, ${ }^{18}$ fashion principles, trade practices, product development techniques ${ }^{19}$ and transitional experiences of the fashion design graduate ${ }^{20}$ and even why students want to pursue a career in fashion, ${ }^{3}$ but very few studies have been conducted on the students' awareness or familiarity with the perceived value placed on of NASADs' accreditation standards for fashion programs. If NASAD is to be a good indicator for the curriculum criteria of art/design programs, are students aware of this when choosing a particular school to attend? This study examined if fashion students are aware or familiar with the perceived value of NASADs' accreditation standards for art/design programs and if accreditation is relevant to prospective students.

\section{Research question}

The following research question guided this study:

i. To what extent, if at all, are fashion students in Southern California aware, or familiar with NASADs' accreditation standards for fashion programs?

ii. What are the most common criteria used in the students' decision to attend a particular public or private fashion education program?

\section{Relevant literature}

A thorough review of literature was made of other comparable studies to understand if the current issues facing the fashion industry and the effect industry changes are having on fashion education are similar in other specialized fields. This literature review included studies on specialized accreditation for fashion/art and design programs of schools accredited by NASAD and American Association of Family Consumer Sciences (AAFCS). ${ }^{16}$ But very few studies relating to the students' perceived value of specialized accreditation, specifically, NASAD for fashion programs, were found. Prather's study examined aviation curriculum ${ }^{21}$ regarding the following: (a) content-based standards versus outcomes-based course criteria; ${ }^{22}$ (b) the students' perception of accreditation for the aviation field; (c) and what role, if any, such accreditation played on the student decisions as to which aviation program to attend. Bill's study on fashion education for fashion designers in today's creative economy examined why students want to be fashion designers, and what influences their choice of where they will start their education.

\section{AAFCS}

American Association of Family Consumer Sciences (AAFCS) is an accrediting agency for colleges that offer fashion degrees in FCS, formally known as home economics. ${ }^{16}$ Most of these colleges are state funded and offer undergraduate and graduate level degrees. According to the AAFCS, the study of home economics, which emphasized the correlation among home life (cooking, sewing), family, economics, and consumerism, evolved into FCS. AAFCS (2016) was established to accommodate the need for home economics degrees and certifications certifying instructors for upper-level grade schools (K-12), colleges, and sewing education accountability that relates to human development and health needs. ${ }^{16} \mathrm{ADM}$ under the FCS banner is the outcome of home economics. The term home economics may suggest a concern that the standards promulgated by AAFCS accreditation are outdated and not in keeping with the current fashion industry needs. Today, FCS is the study of relationships between people, and the impact on environments, human behavior and consumerism. FCS on the CSU campuses encompasses undergraduate and graduate degrees in six areas, often referred to as option areas: Nutrition, Family Studies, Interior Design, FCS Education, Consumer Science, and ADM. The sewing part of the home economics of the past falls under the area of ADM in FCS. Apparel Design, Apparel Merchandising (ADM) in FCS on CSU campuses offers undergraduate degrees in Apparel Design, Apparel Merchandising, Textiles, and Apparel Marketing.

\section{NASAD}

National Association of Schools of Art and Design (NASAD) is composed of approximately 323 collegiate schools of art and design but also includes postsecondary non-degree-granting schools for visual art disciplines. According to ${ }^{2,13}$ there is a significant gap when it comes to matching academic readiness with industry expectations. NASAD standards intend to inject an atmosphere of understanding and respect among schools and departments that combine art and design. The primary mission of NASAD is to offer accreditation membership to educational programs that meet established curricular standards and guidelines for art and design disciplines.

Fashion design, fashion marketing, fashion merchandising, and retail curricula, standards, and guidelines often include content or coursework in fields deemed appropriate to education in a design specialization. ${ }^{12}$

Although these areas of the fashion trade are different specialized fields, they all share an interest in particular content that usually addresses various purposes, perspectives, and structure in their study, and produces different results. Within these specific majors, institutions designate the possibility of areas of emphasis, minors, or option areas (e.g., a Bachelor of Fine Arts in Design may include areas of focus in various design specializations). Typically, coursework in a field of emphasis in liberal arts or Bachelor of Fine Arts studio program is no less than

Twenty five-thirty percent of the total credits designated as a major, and coursework in a minor is at least $12 \%$ (NASAD, 2016: Section IV.C. Pg. 83 b-d). Specific majors may allow areas of emphasis or minors. For example, a Bachelor of Arts with a major in Art provides Painting, Printmaking, Art History, etc., as areas of focus. A Bachelor of Fine Arts in Design may include areas of focus in studio specializations (i.e., sculpting, pottery). Typically, coursework in an area of focus occupies at least $30 \%$ of the curriculum and $12 \%$ 
coursework in a minor. ${ }^{12}$

NASAD versus AAFCS: AAFCS accreditation accommodates fashion courses that apply to human and health development. The NASAD accreditation is specific to the evolving field of creative as well as industrial design for private and public colleges that combine art with design.12 This study focused on specialized programs that combine art and design with fashion programs at public and private institutions. In that regard, the perceived value of NASAD accreditation and their standard criteria was the focus of this study.

\section{Methods}

The participants consisted of 100 students: fifty students enrolled in fashion programs at a 4-year California State University (CSU) public college and (b) fifty students enrolled in fashion programs at a 4-year private college from the Los Angeles area of Southern California. This study aimed to research the current perceived value of NASAD accreditation by seeking the perceptions of these two groups of fashion students from NASAD-accredited 4-year colleges. To meet this objective, the study was guided by two research questions related to the following variables:

The students' their awareness, familiarity or the perceived value of NASADs' accreditation standards for fashion programs, and

Identify other common criterions used in the students' decision when choosing a particular fashion program or school to attend. The survey instrument for this study contained eight quantitative questions.

To analyze the responses, the various data analysis techniques also contained content analysis in every possible instance to facilitate a deeper understanding of how the data addressed the research questions. Even though some of the related literature is over 20 years old, the findings were similar to those obtained in this current research study.

\section{Findings}

Research question 1: To what extent, if at all, are fashion students in Southern California familiar with NASADs' accreditation standards for fashion programs? The findings included tables that show the means and standard deviations for the fashion students who were aware or familiar with NASAD.

Survey items \#3 through \#7 (using a Likert scale) asked about the participant's level of awareness of NASAD accreditation (Table 1).

Survey item \#2 asked participants to state whether they were currently attending a NASAD-accredited school/program responding yes, no, or don't know (Table 2).

Survey question Item \#8 (using no-value versus high-value scale) examined the perceived value students place on NASADs' standards for art and design programs (Table 3 ).

Table 1 shows the participants' level of awareness, or familiarity of NASAD, sorted by highest mean. Ratings were based on a five-point metric: $1=$ Strongly Disagree to $5=$ Strongly Agree. The highest level of agreement was earned for "Unaware of NASAD accreditation" (M $=4.19, \mathrm{SD}=1.15)$, while the lowest level of agreement was earned for "Employers prefer NASAD accredited graduates" $(\mathrm{M}=3.42, \mathrm{SD}$ $=0.99$ ).

Table 2 shows the frequency counts for whether the student was aware that the program he/she was currently attending was NASADaccredited. Students knew the program or school was NASADaccredited $(23 \%)$, believed that they did not attend a NASAD accredited fashion program (34\%), or did not know if the program they were currently attending was NASAD-accredited (43\%).

Table 3 represents on a scale of 1 to 10 (with 1 representing no value and 10 representing high value), how valuable you feel NASAD accreditation is to you as a student? $1=$ No Value to $10=$ High Value with a mean of $\mathrm{M}=6.78$ and $\mathrm{SD}=2.35$. This survey item was created to add more support to research question 1 . Students responded to this question by selecting a level of 1 to 10 regarding the value they place on NASAD. $12 \%$ selected a level between 1 to 3 , while $55 \%$ selected a level from 5 to 7 , and $33 \%$ placed the highest level of 8 to 10 on the perceived value of NASAD accreditation.

Research question 2: What are the most common criteria used in the students' decision to attend a particular public or private fashion education program? Using frequency counts, survey items $1 \mathrm{~A}-1 \mathrm{~N}$ was developed to answer this question. Students were asked to select (from 14 categories) 1 or more common criteria they found important to them when deciding on a particular fashion program or school to attend (Table 4).

Table I Means and Standard Deviations for Survey Items 3-7

\begin{tabular}{lll}
\hline Item & M & SD \\
\hline Unaware of NASAD accreditation & 4.19 & 1.15 \\
Decision based on other factors & 3.96 & 1.09 \\
Greatly benefit students program NASAD accredited & 3.52 & 0.78 \\
Important to attend NASAD accredited program & 3.52 & 0.73 \\
Employers prefer NASAD accredited graduates & 3.42 & 0.99
\end{tabular}

Table 2 Frequency Counts for Survey item \#2 (N=100)

\begin{tabular}{llll}
\hline Variable & Category & $\mathbf{n}$ & $\%$ \\
\hline Attend NASAD accredited fashion & Yes & 23 & 23 \\
program & No & 34 & 34 \\
& Don't Know & 43 & 43 \\
\hline
\end{tabular}

Note: $\mathrm{n}=\#$ of students who answered the question

Table 3 Frequency Counts for $\mathrm{I}=$ No Value to $10=$ High Value $(N=100)$

\begin{tabular}{llll}
\hline Variable & Rankings & n & $\%$ \\
\hline NASAD accreditation value & I to 3 & 12 & 12 \\
5 to 7 & 55 & 55 \\
8 to 10 & 33 & 33 \\
\hline
\end{tabular}

!'Rankings given as $\mathrm{I}=$

Table 4 shows the frequency counts sorted by highest frequency $(\mathrm{N}=100)$ of the common criteria used in the students' decision to attend a particular public or private fashion education program. Location of school $(88 \%)$ and specific academic program (i.e., fashion design, fashion merchandising; 87\%) were the number one and number two most common criteria among students from both schools. However, cost (86\%), financial aid/scholarships (85\%), and reputation of school $(80.0 \%)$ were also in the $20 \%$ percentile. Job 
assistance (77\%), attending a 4-year program $(73 \%)$, reputation of the program (62\%) and NASAD accreditation (59\%) received moderate responses. Particular professor $(17 \%)$, friends $(10 \%)$, and alma mater $(8 \%)$ received the lowest response counts.

Table 4 Frequency Counts for Common Factors When Selecting a Fashion Program and Institution Sorted by Highest Frequency $(\mathrm{N}=100)$

\begin{tabular}{lll}
\hline Rating & $\mathbf{n}$ & $\%$ \\
\hline Location of School & 88 & 88 \\
Specific academic program & 87 & 87 \\
Cost & 86 & 86 \\
Financial Aid/Scholarships & 85 & 85 \\
Reputation of School & 80 & 80 \\
Help Me Find A Job & 77 & 77 \\
4-year fashion program & 73 & 73 \\
Reputation of the program & 62 & 62 \\
NASAD accreditation & 59 & 59 \\
Fashion Studio Facilities & 49 & 49 \\
Accreditation Standing & 42 & 42 \\
Particular professor & 17 & 17 \\
Friends & 10 & 10 \\
Alma Mater & 8 & 8 \\
\hline
\end{tabular}

\section{Results}

Results of the findings for the collected data were interpreted and displayed in tables. These results include: (a) how the results answered the research question and (c) explanation of the findings as they pertain to the hypothesis. Although the findings would provide sufficient evidence to conclude that there is a certain amount of unawareness or familiarity of NASAD among 100 Southern California collegiate fashion students, these students seem to believe there is some sort of perceived value in NASADs' accreditation standards for their fashion education.

Research question 1: Awareness, familiarity or the perceived value of NASAD. Three survey items asked each participant to rate their level of awareness of NASAD. The responses revealed a high level of unawareness of NASAD criteria.

Research question 2: Most common criteria when choosing a particular fashion program or school. Students were given fourteen categories to choose from, using the frequency of responses, the most common criteria (in order)were: location of school (88\%); specific program offered (87\%), cost (86\%), financial aid/scholarships (85\%), reputation of the institution ( $80 \%$ ), the assistance from the school to help find a job (77\%), must be a 4-year program (73\%), reputation of the particular program (62\%), NASAD status (59\%), studio facilities $(49 \%)$, institution status $(42 \%)$, particular professor $(17 \%)$, friends attending (10\%), and family alma mater (8\%).

Key findings: Research for this study found the following: (a) $80 \%$ of students were unfamiliar with NASAD standards for fashion programs and (b) unaware if they are attending a NASADaccredited program, (c) while $57 \%$ felt there is some value to NASAD accreditation, only $45 \%$ of the students felt NASAD accreditation was an important criteria when choosing a school.

\section{Conclusion, assumptions, implications \& recommendations}

\section{Conclusion}

The title of this study, "The Perceived Value of the National Association of Schools of Art and Design (NASAD) Accreditation by Fashion Students in Fashion Programs at Public and Private Colleges," represents the variables awareness, familiarity or perceived value of NASAD. Compared to other studies, other specialized fields like aviation, parks-recreation and nursing,who require certification, examination licenses, and specific training for transition from academic education, similar to the fashion industry. The findings from this study, regarding the awareness, familiarity or the perceived value of specialized accreditation standards for fashioner other programs may have nothing to do with their decisions when deciding which program or school to attend. Instead, the choice of school or program is influenced by other criteria. The findings for this study were similar to several other studies.

Students at both NASAD-accredited schools equally were unaware or unfamiliar with NASADs' accreditation standards for fashion programs: $61 \%$ of the students were not aware of NASAD or NASADs' standards as a good indicator for quality fashion education. This was consistent Prather's study on aviation training and education, which found that $60 \%$ of aviation students he surveyed tended to agree that they were unaware of AABI standards.21 As far as perceived value place on accreditation, the responses indicate the students believe there is or should be high value placed on NASADs' standards for fashion education; although, the same level of value did not influence their decision when choosing a particular fashion program. This finding was also consistent with Prather's aviation study.21 He found students took the middle ground (5.386) when it came to placing a high value on accreditation or recognizing specialized accreditation as a good indicator of higher quality curriculum criteria, faculty recruitment, and exam training when choosing a particular school or program to attend. Bill's study on educating designers for a creative economy found that students who wanted to be designers, specifically in the area of fashion, chose schools based other criteria that had nothing to do with the quality of the education, or any accreditation status or value.

Location of school, cost, and financial aid/scholarships when deciding where to begin their fashion education was concluded the most common criterions when choosing a school. Although some studies suggested that one of the most common criteria used in the students' decision to attend a particular public or private fashion education program was status and prestige of a particular college, other studies revealed confidence in faculty and student career assistance were major decision influencers. As well as the reputation of a specific program (i.e., fashion merchandising program), which was similar to Litwack's study on nursing. Litwack's study indicated that facilities and job placement were more important factors when choosing a program to begin their nursing training than the accreditation status of the school or program.23,24 She also found exam scores at nonaccredited programs (exams required for nursing certification), were higher than students attending accredited nursing programs. With that said, accreditation would not be considered an important decision criterion when choosing a school, although of the 100 students 
surveyed for this study, 59 students felt NASAD accreditation status should be an influencer when deciding on a particular fashion school to attend.

\section{Assumptions}

The literature overview for this study suggests program administrators realize the benefits of NASAD accreditation, including improved credibility, protection of the program, and positioning of the program as a leader in collegiate fashion. This assumption suggests, once the program and school are NASAD-accredited (even though the process may have required a great deal of work on the part of faculty and administration), the benefits seem to outweigh the costs. These findings surely challenge existing assumptions. For instance, administrators of NASAD-accredited programs point to their NASAD accreditation status on schools websites as important in marketing and attracting high quality students to specific programs. When measuring the level of awareness of NASAD, schools, marketing departments, and administrators seem well aware of NASAD. However, the level of awareness seems to go no further than administrators.

Students, for instance, were generally unaware of NASAD accreditation, general.

Perceived value: A frequently challenged assumption is that NASAD-accredited programs indicate accreditation membership ensures that specialized programs meet standards established by the profession." However, $43 \%$ percent of responding students in this study were not even aware if their program was accredited before receiving the survey. Participants from both schools responded in similar ways to questions regarding the value they place on NASAD accreditation. Even though the majority of current fashion students are not aware of neither NASAD, nor do they know whether or not the program they currently attend is accredited by NASAD, there was a shared agreement that there is some sort of high value placed on NASAD (29\%). This finding is not only important, but also interesting, in that the lack of awareness only seems to be an issue among collegiate fashion students.

\section{Implications}

Fashion Students: The perceived value of NASAD accreditation among students was the main objective of this study. As determined by the statistical analysis of the data related to research question 1 , most students felt there is some type of value in NASAD accreditation, but not to them. Studies by Roller et al.,9 and the Business of Fashion found that many educational non-accredited institutions hold administration and departments chairs accountable for program improvements, marketing advantages, faculty recruitment; not the membership to an accrediting agency.25,26

Perceived value: To support the fact that students never asked if their program was accredited, challenging assumptions of academia and NASAD that schools or fashion program websites with NASAD accreditation advertised are not registering with prospective students. Although schools advertise on their websites they are accredited through NASAD, many students may not care about this fact if they generally feel confident enough to transition into the field, and there is no requirement that graduating from a NASAD-accredited program is required for job placement (as in other fields where national certification/licensure tests require the applicant to have graduated from an accredited program). It appears that neither the NASAD nor the schools are meeting the needs of various stakeholders (such as students and industry employers). To question the degree, to which NASAD has fulfilled its original purpose, is found in the lack of awareness of NASAD? The most responses received by students were for "Prior to receiving this survey, I was unaware of the National Association of Schools of Art and Design (NASAD) accreditation" (CSU 31\% and private 30\%, respectively).

NASAD: As noted previously, NASAD (2016) supports several specific purposes:

Curriculum standardization

Courses being parallel to needed industry skills

Students learning contemporary product development standards

Offering directives on how to protect students and other stakeholders against academic fraud.

On the surface, it appears that NASAD is generally fulfilling these purposes. However, if NASAD has accomplished some curriculum standardization within collegiate fashion, it is not clear if the universities and other stakeholders have fulfilled their promises to students, as outlined by NASAD. Students not knowing if they are attending a NASAD-accredited program or being aware enough awareness to ask if the program is NASAD-accredited further complicate the issue.

Perceived value: If there is no demand for NASAD accreditation from the students attending fashion programs, there will not be demand for NASAD accreditation. If future college students do not seek out NASAD-accredited programs and industry employers do not demand graduates be from NASAD-accredited programs, and then what is the purpose of accreditation? Understandably, without demand for NASAD-accredited fashion programs, a good reason a program would seek NASAD accreditation is for self-improvement, but the time and effort to acquire a fashion degree, if upon completion, it is only recognized by the family, the student may feel cheated out of the quality education they may have sought in the first place.

NASAD-accredited programs: A substantial interest in maintaining NASAD accreditation for the surveyed institutions to some degree, the position in which NASAD and collegiate fashion finds itself today seems to be only recognized by academia. Many students want their degree, especially one earned from a NASAD-accredited promoted fashion program, to assure job placement.

Job placement: A little over half of the responding students felt NASAD does not offer any direct or indirect benefits to job placement or current faculty experience. In contrast, if faculty is not familiar with current industry standards, procedures, or NASAD structure; curricula will not be questioned or updated, which affects the standards of collegiate fashion instruction and program.

\section{Recommendations}

College placement: The perceived value amongst fashion students could be brought to greater heights. The lack of awareness of NASAD could be attributed to high school guidance counselors and their lack of awareness and knowledge regarding the purpose and benefits of NASAD. To increase the awareness of NASAD accreditation among potential fashion students and those who assist in college placement, should acknowledge, that students need to be captured before deciding about which institution and fashion program to attend. 
Marketing: Due to the lack of understanding regarding the perceived value students place on NASAD as a good indicator of what a quality fashion education should entail; NASAD should develop a comprehensive marketing program towards the various stakeholders (prospective students, parents and recruiting schools). This particular recommendation could ignite a realization in the fashion industry that the benefits of NASAD accreditation, enhance and provide more confidence when hiring graduates; knowing the student graduated from a NASAD-accredited program.

\section{Is NASAD relevant to the current fashion student?}

Very few students considered the NASAD accreditation status of a program necessary when selecting an institution to attend or that the NASAD name did little to influence potential students to choose a specific fashion program. A more aggressive marketing campaign from NASAD to the many prospective collegiate fashion students intending or pursuing a fashion career could help in widening the awareness of their mission. Likewise, NASAD-accredited programs should ensure that students considering their program are well aware of NASAD, to capture students for recruiting purposes. The NASADs' standards are a good indicator for starters, if only to recognize what a quality fashion program should entail. It is however disappointing to learn how few collegiate fashion students are even aware if they were attending a NASAD-accredited school, or what NASAD means. In particular, as compared to other academic fields, several of the public and private colleges surveyed for this study are not offering specific content-courses that parallel pertinent industry needs. Thus, some of these courses need to be added to the NASADs' standards. NASADaccredited fashion programs owe students a quality fashion education, especially if they advertise their NASAD accreditation (on the school's website). A quality fashion education should ensure current instruction is facilitated by current faculty practitioner's who meets industry standards. Only then can NASAD standards be challenged, and continue to align with what the industry wants.

\section{Acknowledgements}

None.

\section{Conflict of interest} article.

Author declares there is no conflict of interest in publishing the

\section{References}

1. Joint Economic Committee. The economic impact of the fashion industry report. 2015

2. Robinson A. The Made in America Movement. Made in the USA \& apparel reshoring: Expert round- up. 2013.

3. Bill A. Educating fashion designers for a creative economy. Anti-po-des Design Journal. 2003.

4. Bell CA, Youngs P. Substance and show: Understanding responses to teacher education programme accreditation processes. Teaching \& Teacher Education. 2011;27(2):298-307.

5. Bitter ME, Stryker JP, Jens WG. A preliminary investigation of the choice to obtain AACSB accounting accreditation. Accounting Educators' J. 1999;11:1-15
6. McFadden C, Sheerer M. Faculty members' perceptions of teacher preparation programs. Educational Forum. 2006;70(1):61-74.

7. Pringle C, Michel M. Assessment practices in AACSB-accredited business schools. J Education Business. 2007;82(4):202-11.

8. Roberts WA, Johnson R, Groesbeck J. The perspective of faculty hired after AACSB accreditation on accreditation's impact and importance. Academy of Educational Leadership J. 2006;10(3):59-71.

9. Roller RH, Andrews BK, Bovee SL. Specialized accreditation of business schools: A comparison of alternative costs, benefits, and motivations. $J$ Education for Business. 2003;78(4):197-204.

10. Wood AL. Demystifying accreditation: Action plans for a national or regional accreditation. Innovative Higher Education. 2006;31(1):43-62.

11. Zionts LT, Shellady SM, Zionts P. Teachers' perceptions of professional standards: Their importance and ease of implementation. Preventing School Failure. 2006;50(3):5-12.

12. National Association of Schools of Art and Design. NASAD handbook. 2016.

13. Robinson A. Manufacturing industry trends in America: The final four of 8.2013.

14. Lowson B, King R, Hunter A. Quick response: Managing the supply chain to meet consumer demand. Chichester: Wiley; 1999.

15. Council for Higher Education Accreditation. CHEA-at-a-Glance. 2015

16. American Association of Family and Consumer Sciences. 2016.

17. Browne LB, Myers L, Gentzler YS, et al. Effectiveness of secondary family and consumer sciences programs (1985-2004). J Family \& Consumer Sciences. 2006;98(1):26-32.

18. Wang L. The burgeoning business of fashion education. 2013.

19. Faerm S. Towards a future pedagogy: The evolution of fashion design education. International J Humanities \& Social Sciences. 2012;2(23):210-19.

20. Faerm S. From classroom to design room: the transitional experience of the fashion design graduate. Cuadernos del Centro de Estudios en Diseño y Comunicación. 2014;48:129-52.

21. Prather CD. Specialized accreditation in collegiate aviation: An analysis of the perceived value of specialized accreditation by the aviation accreditation board international. Lincoln: University of Nebraska; 2007.

22. Auburn AL. Council on Aviation Accreditation. Accreditation standards manual. 2003.

23. Litwack KP. Specialized accreditation of baccalaureate nursing programs in the United States. Ohio: Kent State University; 1986.

24. Litwack KP. The future of nursing: You can't use knowledge you don't have. J Peri Anesthesia Nursing. 2013;28(3):192-3.

25. Business of Fashion. BOF Global fashion school rankings 2017. 2017.

26. US Department of Labor, Bureau of Labor Statistics. Occupational outlook handbook: Arts and design occupations. 2017. 